\title{
Bilateral communication between musculocutaneous and median
} nerve

\author{
Chandrika G.Teli ${ }^{1}$, H.S.Kadlimatti ${ }^{2}$, Nilesh N. Kate ${ }^{3}$ \\ ${ }^{1}$ (Department of Anatomy, ESIC Medical College,Gulbarga/ Rajiv Gandhi university of health sciences \\ Karnataka, India) \\ ${ }_{2}^{2}$ (Department of Anatomy, ESIC Medical College,Gulbarga/ Rajiv Gandhi university of health sciences \\ Karnataka, India) \\ ${ }^{3}$ (Department of Physiology, ESIC Medical College, Gulbarga/ Rajiv Gandhi university of health sciences \\ Karnataka, India)
}

\begin{abstract}
The brachial plexus is the most variable part of the peripheral nervous system. The prevalence of variations ranges from 12.8 up to 53\%. In this case we report variant communication between musculocutaneous and median nerve in both the upper limbs of a 50 year old male cadaver. The communicating branch arose from the musculocutaneous nerve. Without piercing coracobrachalis, musculocutaneous nerve gave motor braches to coracobrachialis muscle. At middle of arm musculocutaneous nerve gave three branches, one suppling brachialis, second passing between biceps brachii and brachialis which continued as lateral cutaneous nerve of forearm, third branch joined the median nerve. Such communications usually reported are unilateral, bilateral variant is reported here. We endeavour to discuss the relevance of embryogenesis and clinical significance of the condition.
\end{abstract}

Keywords: brachial plexus, musculocutaneous nerve, median nerve, communications

\section{INTRODUCTION}

The brachial plexus is the most variable part of the peripheral nervous system [1]. The prevalence of variations ranges from 12.8 up to $53 \%$ [1,2].The musculocutaneous nerve is derived from the lateral cord of the brachial plexus and its muscular recipients are: the biceps brachii, coracobrachialis, and the brachialis. Additionally, this nerve supplies the lateral margin of the skin of the forearm. After branching to form the musculocutaneous nerve, the lateral cord continues as a lateral root of the median nerve, joining the medial root at the level of the distal margin of the pectoralis minor muscle in front of the axillary artery. The median nerve does not have any muscular branches in the arm. Variations of the musculocutaneous nerve may occur in $6.25 \%$ of cases. [3] Many authors have mentioned about the occurrence of communication of the musculocutaneous and median nerve, but bilateral occurrence is rare and been cited once only to the best of our knowledge.

The musculocutaneous nerve arises from the lateral cord in $90.5 \%$, from the lateral and posterior cord in $4 \%$, from the medial cord in $2 \%$ and has two separate bundles from the medial and lateral cords in $1.4 \%$. [4] Sometimes it sends a branch back to the median nerve in the brachium. $[5,6]$ some fibres of the median nerve may run in the musculocutaneous nerve leaving it to join their main trunk. [5]The introduction of the paper should explain the nature of the problem, previous work, purpose, and the contribution of the paper. The contents of each section may be provided to understand easily about the paper.

\section{Case Report}

During routine dissections for undergraduates, variant communication between musculocutaneous and median nerve was noted in both the upper limbs of a 50 year old male cadaver. The communicating branch arose from the musculocutaneous nerve. Without piercing coracobrachalis, musculocutaneous nerve gave motor braches to coracobrachialis muscle then to biceps brachii. At middle of arm musculocutaneous nerve gave three branches, one suppling brachialis, second passing between biceps brachii and brachialis which continued as lateral cutaneous nerve of forearm, third branch joined the median nerve, at a distance of $15 \mathrm{~cm}$ and $16 \mathrm{~cm}$ from the tip of coracoid process on right and left side respectively. Further course and relations of MCN were found to be without any variation.

\section{Discussion}

Anastomosis between the MCN and the MN is by far the most common and frequent of all the variations that are observed among the branches of the brachial plexus [7]. Fibres of the MN run along with the MCN, which after travelling some distance, leave the later to join the parent trunk (8). These communications between MN and MCN have been classified into five types (9). In type I, there is no communication between the MN and the MCN, in type II, the fibres of the medial root of the MN pass through the MCN nerve and join 
the MN in the middle of the arm, whereas in type III, the lateral root fibres of the MN pass along the MCN and after some distance, leave it to form the lateral root of the MN. In type IV, the MCN fibres join the lateral root of the MN and after some distance the MCN arises from the MN. In type V, the MCN is absent and the entire fibres of the MCN pass through the lateral root and fibres to the muscles supplied by MCN branch out directly from the MN. Connection between the MCN and MN in the present study could not be incorporated into any of the types described by Le Minor (1992) as it showed communication, which was not included in his description. Venieratos and Anangnostopoulou (1998) have described only three types of communications between the $\mathrm{MCN}$ and MN in relation to the coracobrachialis muscle. In type I, communication between MCN and MN is proximal to the entrance of the MCN into the coracobrachialis, whereas in type II, the communication is distal to the muscle and in type III neither the nerve nor its communicating branch pierced the muscle. According to this classification the communication, noted in our study can be placed in type III, as the MCN did not pass through the coracobrachialis muscle. The most frequent variation is the presence of a communicating branch that bifurcates from the MCN and goes distally to join the MN, an anastomosis observed in the lower third of $\operatorname{arm}(7,10)$. If this branch is given off in upper third of the arm, it is generally considered as third (double lateral) root of the median nerve.

The interpretation of the nerve anomaly of the arm requires consideration of the phylogeny and development of the nerves of the upper limb. Communication between the MCN and MN is considered as a remnant from the phylogenetic or comparative point of view. Imokawa (cited from Kosugi et al. 1986 [11]) reported that there was only one trunk equivalent to the $\mathrm{MN}$ in the thoracic limb of the lower vertebrates (amphibians, reptiles and birds). In the context that ontogeny recapitulates phylogeny; it is possible that the variation seen in the current study is the result of developmental anomaly. In man, the forelimb muscles develop from the mesenchyme of the para-axial mesoderm during fifth week of embryonic life (12). The axons of spinal nerves grow distally to reach the limb bud mesenchyme. The peripheral processes of the motor and sensory neurons grow in the mesenchyme, in different directions $(8,13)$. Although it is unclear why neuronal processes assemble to form a mixed nerve, in this complex developmental event, there are multiple possibilities for the route taken by developing axons and thus for their arrival at the main trunk. Once formed, any developmental differences would obviously persist postnatally (13). As the guidance of the developing axons is regulated by expression of chemoattractants and chemorepulsants in a highly coordinated site specific fashion any alterations in signaling between mesenchymal cells and neuronal growth cones can lead to significant variations (14). Specifically, such developmental abnormalities for axonal guidance in the coracobrachialis muscle could readily produce situation where the MCN does not pass through the coracobrachialis muscle, as seen here (7). Alternatively, the variation could arise from circulatory factors at the time of fusion of the brachial plexus cords (11). Cases of communication between the $\mathrm{MN}$ and $\mathrm{MCN}$ or $\mathrm{MN}$ and $\mathrm{UN}$ variations are apparently not rare, and it is possible that the combined lesion of the MCN and part of MN would occur in injury of the lateral cord of the brachial plexus. Lesions of the communicating nerve may give rise to patterns of weakness that may impose difficulty in diagnosis. Clinical implication of this could be that injury of MCN proximal to the anastomotic branch between MCN and MN may lead to unexpected presentation of weakness of forearm flexors and thenar muscles (15). MN and MCN might be of importance to the surgeons, diagnostic clinical neurophysiology, traumatology.

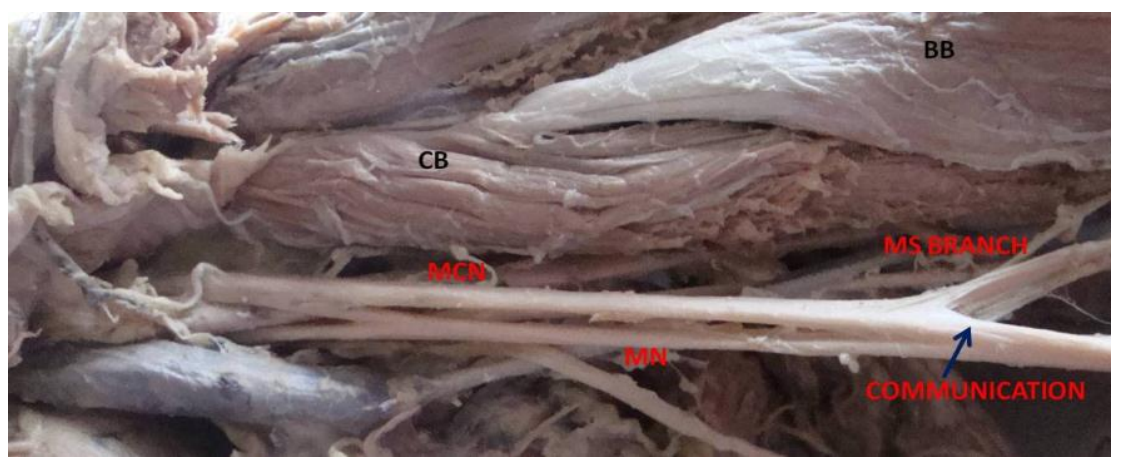

Fig 1: Left upper limb showing, the musculocutaneous nerve [MCN], Without piercing coracobrachalis [CB], gave motor braches to coracobrachalis $[\mathrm{CB}]$, brachialis and biceps brachii $[\mathrm{BB}]$ muscle. At middle of arm MCN

gave three branches, one suppling brachialis [Ms BRANCH], second passing between biceps brachii and brachialis which continued as lateral cutaneous nerve of forearm, third branch [COMMUNICATION] joined the median nerve. 


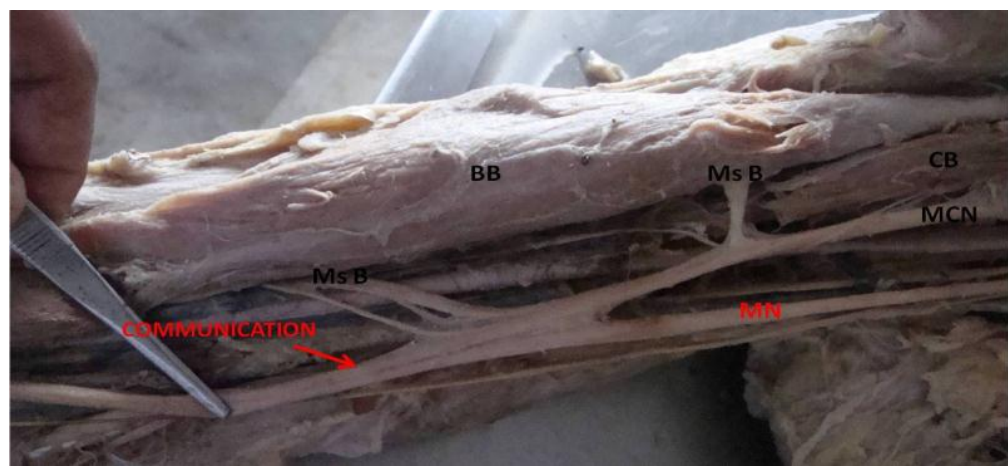

Fig 2: Right upper limb showing, the musculocutaneous nerve [MCN], Without piercing coracobrachalis [CB], gave motor braches to coracobrachalis $[\mathrm{CB}]$, brachialis and biceps brachii [BB] muscle. At middle of arm $\mathrm{MCN}$

gave three branches, one suppling brachialis [Ms BRANCH], second passing between biceps brachii and brachialis which continued as lateral cutaneous nerve of forearm, third branch [COMMUNICATION] joined the median nerve.

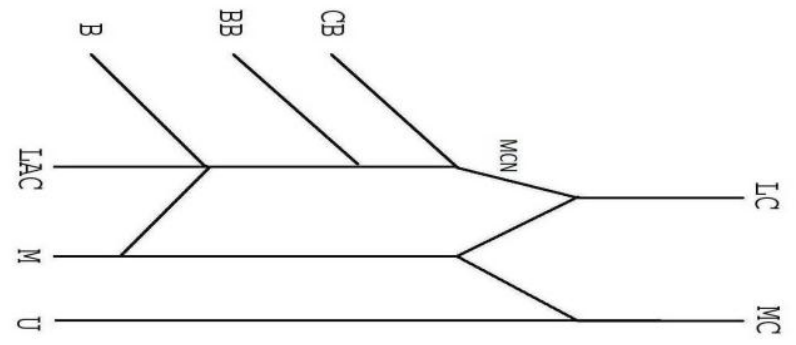

Fig 3: Schematic diagram showing communication between the musculocutaneous nerve and median nerve reported in present study.

\section{References:}

[1] Johnson E, Vekris M, Demesticha T, Soucacos P (2010) Neuroanatomy Of the brachial plexus: normal and variant anatomy of its formation. Surg Radiol Anat 32:291-297

[2] Pandey SK, Shukla VK (2007) Anatomical variations of the cords of brachial plexus and the median nerve. Clin Anat 20(2):150156

[3] Bhattarai C, Poudel PP (2009) Unusual variation in musculocutaneous nerves. Kathmandu Univ Med J 7:408-410

[4] Tountas and Bergaman Anatomic variations of upper extremity New York Churchill Livingstone 1993

[5] Williams PL, Warwick R, Dyson M, Bannister LH. Gray’s anatomy. $37^{\text {th }}$ edition. London: Churchill Livingstone; 1989

[6] Arora L, Dhingra R (2005) Absence of musculocutaneous nerve and accessory head of biceps brachii: a case report. Indian J Plast Surg 38:144-146

[7] Venieratos, D. and Anangnostopoulou, S. (1998): Classification of communications between the musculocutaneous and median nerves. Clinical Anatomy. 11: 327-331.

[8] Williams, P.L., Bannister, L.H., Berry, M.M., Collins, P.,Dyson, M., Dussek, J.E. and Ferguson, M.W.J.: Gray’s Anatomy In: Nervous system. 38th Edn; Churchill Livingston. Edinburgh. pp:1266-1274(1995).

[9] Le Minor, J.M. (1992): A rare variant of the median and musculocutaneous nerves in man. Archieves Anatomy Histology Embryology. 73: 33-42.

[10] Bergman, R.A., Thompson, S.A., Afifi, A.K. and Saadeh, F.A.: Compendium of human anatomic variation. Urban \&Schwarzeberg Munich. pp 139-143. (1988).

[11] Kosugi, K., Mortia, T., Yamashita, H. (1986): Brancing pattern of the musculocutaneous nerve. 1. Cases possessing normal biceps brachii. Jikeakai Medical Journal. 33: 63-71.

[12] . Larsen, W.J.: Human Embryology In. Development of limbs.2nd Edn; Churchill Livingstone. Edinburgh. pp 311-339.(1997).

[13] Brown, M.C., Hopkins, W.G. and Keynes, R.J.: Axon guidance and target recognition In : Essentials of neural development. Cambridge University Press. Cambridge. Pp 46-66. (1991)

[14] Sannes, H.D., Reh, T.A. and Harris, W.A.: Development ofthe nervous system In: Axon growth and guidance. Academic Pres. New York. pp 189-197. (2000).

[15] Sunderland, S.: Nerves and Nerve Injury In: The Median Nerve: Anatomical and Physiological features. 2nd Edn; Churchill Livingstone. Edinburgh. pp 672-677, 691 727. (1978). 